\title{
NUMERICAL SIMULATION OF FCC RISERS
}

\author{
J. A. Souza \\ J. V. C. Vargas ${ }^{\mathrm{a}}$, \\ O. F. Von Meien ${ }^{a}$, \\ and W. Martignoni ${ }^{\mathrm{b}}$, \\ ${ }^{a}$ Universidade Federal do Paraná \\ PIPE - Programa Interdisciplinar de \\ Pós-Graduação em Engenharia \\ Centro Politécnico \\ ABSTRACT \\ The catalytic cracking of hydrocarbons in a FCC riser is a very complex \\ physical and chemical phenomenon, which combines a three-dimensional, \\ three-phase fluid flow with a heterogeneous catalytic cracking kinetics. \\ Several researchers have carried out the modeling of the problem in different \\ ways. Depending on the main objective of the modeling it is possible to find \\ in the literature very simple models while in other cases, when more \\ accurate results are necessary, each equipment is normally treated separately \\ and a set of differential and algebraic equations is written for the problem. \\ The riser reactor is probably the most important equipment in a FCC plant. \\ All cracking reactions and fuel formation occur during the short time (about \\ 4-5s) that the gas oil stays in contact with the catalyst inside the riser. This \\ work presents a simplified model to predict the, temperature and \\ concentrations in a FCC riser reactor. A bi-dimensional fluid flow field \\ combined with a 6 lumps kinetic model and two energy equations (catalyst \\ and gas oil) are used to simulate the gas oil cracking process. Based on the \\ velocity, temperature and concentration fields, it is intended, on a next step, \\ to use the second law of thermodynamic to perform a thermodynamic \\ optimization of the system.
}

\section{INTRODUCTION}

The Fluid Catalytic Cracking (FCC) process represents nowadays an important segment for the petroleum industry. It is the key process for the profitable conversion of heavy hydrocarbon molecules into products of commercial interest like gasoline, light olefins and LPG. With the FCC process the residual fractions of the atmospheric and vacuum distillation are reprocessed reducing the amount of residues sent to the environment.

All conversion of heavy petroleum fractions into lower molecular-weight products takes place at the riser reactor which is a long tube with a proportionally smaller diameter. At the riser bottom, a liquid stream of gas oil flowing through a number of nozzles is brought into contact with the hot catalyst coming from the regenerator, and almost instantaneously, the gas oil feed is vaporized. This inlet zone is characterized by the presence of turbulence and high gradients of concentrations and temperature. This three-dimensional, three-phase fluid flow phenomenon is important, but it happens only at the first few meters of the riser and normally takes about $0.1 \mathrm{~s}$, which represents only $3 \%$ of the mixture residence time in the riser (Ali and Rohani, 1997). Therefore, based on this assumption, it is explainable that many of the models found in the literature describe the riser reactor with onedimensional mass, energy and chemical species balances. Next, the various modeling approaches found in the lecture will be briefly discussed.

The first type of riser modeling is the onedimensional one. These models are normally simple to formulate and to solve. They are more suitable when the interest is to explore the influence of operating conditions, test a kinetic model or when the simulation includes not only the riser, but also all FCC unit processes. The simplest kind of these models is the homogeneous version, where both the gas oil and the catalyst are moving at the same velocity and the gas oil is considered to enter the riser totally vaporized (Ali and Rohani, 1997; Blasetti and Lasa,
1997; Cerqueira, et al., 1997; Jacob et al., 1976; Juárez et al., 1999). The heterogeneous version considers different velocities for the gas and the particulate, resulting in different resident times for the gas oil and the catalyst inside the riser (Han and Chung, 2001). Martignoni and Lasa, 2001, developed a one-dimensional model where a pseudo-three-phase flow is considered.

The second type includes the semi-empirical models, which are usually described as core-annulus models. Normally the particle fall velocity and particle concentration are determined empirically. These models cannot predict results for different operational conditions from those of the model parameter estimation. However, the models have a simple formulation and the numerical solution is easily obtained (Deroin et al., 1997; Patience et al., 1992).

More detailed than the above discussed models, are those that consider the riser reactor as bi or threedimensional. These models are based on phenomenological concepts and use a simultaneous solution of the conservation equations of mass, momentum, energy and species for both the gas and particulate phases (Gao et al., 1999; Mathiesen, et al., 1999). The physical properties are not necessarily, assumed constant and additional equations must be set for them. Turbulent models are normally used to describe the fluid flow and in some formulations, the kinetic theory is used to determine the physical characteristics of the particle flow (Neri and Gidaspow, 2000; Tsuji et al., 1997). More recent works have already included in the formulation a third flow-phase, which was added to incorporate the effect of feed vaporization at the entrance region of the riser (Gao et al., 2001). This class of models is clearly more accurate than the two types already discussed, and can be used as a design tool regardless of having or not experimental support. However, they are very complex, difficult to formulate, and in some situations their numerical solution is not even property developed yet (Martignoni, 1998).

It is also of great importance to give some attention to the formulation used for modeling the catalytic 
cracking reactions. The complexity of chemical structure of the gas oil makes it very difficult to describe its kinetics at a molecular level. Therefore, the modeling of such complex process can be simplified by lumping large numbers of chemical compounds with similar behavior. Weekman and Nace, 1970, presented the oldest and also simplest three-lump model to predict the catalytic cracking reactions. Other examples of simple models are the fourlump model proposed by Blasetti and Lasa, 1997, and the five-lump model propose by Juárez et al., 1999. These simple models that describe the cracking kinetics with 3, 4 or 5 lumps have the advantage that just a few kinetic constants must be estimated for each feedstock, but depending on the simplicity of the model, the key FCC products cannot be predicted separately. More sophisticated models, normally with more than 10 lumps, have basically two advantages: a single group of estimated kinetic constants can be used for various feedstock and all the most important FCC products can be predicted separately. The disadvantages of these models are that a large number of kinetic constants must be estimated and as each lump represents a differential equation in the mathematical model, the complexity of the numerical solution may increase exponentially. Examples of these models are the classical 10 lumps model presented by Jacob et al., 1976, the 12 lumps model presented by Cerqueira et al., 1997a and the 19 lumps model presented by Pitault at al., 1994.

In the present work, a 2-D fluid flow field combined with a 6 lumps kinetic model and two energy equations (catalyst and gas oil) are used to simulate the gas oil cracking process inside the riser reactor. Next the mathematical model and some preliminary results are presented.

\section{MATHEMATICAL MODEL}

A general simple problem sketch is shown in Fig. 1. The geometry and the catalyst, gas oil and steam inputs are schematically represented. In Fig. 1, H is the length of the riser in the flow direction and $\mathrm{R}$ the riser's radius.

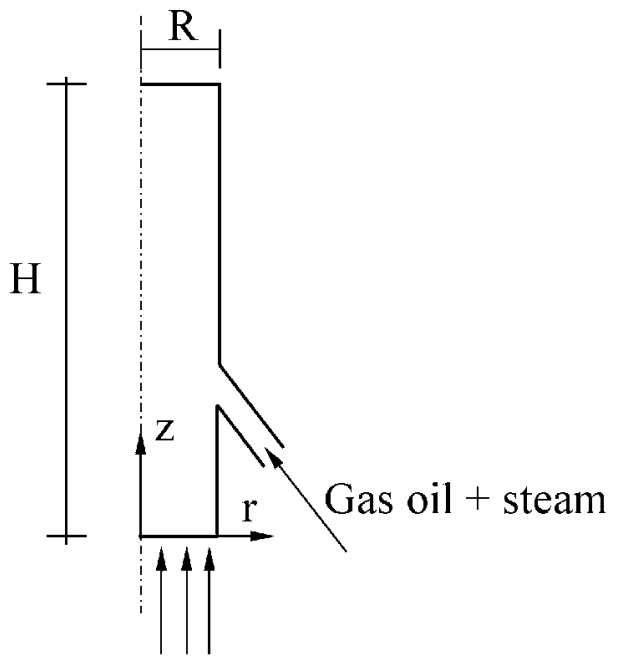

\section{Catalyst + steam}

Fig. 1 - Problem sketch

Although heavy gas oil, steam and particulate catalyst are injected simultaneously in the riser, in this treatment, the moving matter inside the riser is approximated by an equivalent well mixed fluid with an average set of properties. The fluid flow is assumed bidimensional, incompressible and with constant properties. The mass and momentum conservation equations for a Newtonian fluid is given by

$$
\begin{gathered}
\frac{\partial \mathrm{v}_{\mathrm{r}}}{\partial \mathrm{r}}+\frac{\mathrm{v}_{\mathrm{r}}}{\mathrm{r}}+\frac{\partial \mathrm{v}_{\mathrm{z}}}{\partial \mathrm{z}}=0 \\
\rho\left(\frac{\partial \mathrm{v}_{\mathrm{r}}}{\partial \mathrm{t}}+\mathrm{v}_{\mathrm{r}} \frac{\partial \mathrm{v}_{\mathrm{r}}}{\partial \mathrm{r}}+\mathrm{v}_{\mathrm{z}} \frac{\partial \mathrm{v}_{\mathrm{r}}}{\partial \mathrm{z}}\right)=-\frac{\partial \mathrm{p}}{\partial \mathrm{r}}+ \\
\mu\left(\frac{\partial^{2} \mathrm{v}_{\mathrm{r}}}{\partial \mathrm{r}^{2}}+\frac{1}{\mathrm{r}} \frac{\partial \mathrm{v}_{\mathrm{r}}}{\partial \mathrm{r}}-\frac{\mathrm{v}_{\mathrm{r}}}{\mathrm{r}^{2}}+\frac{\partial^{2} \mathrm{v}_{\mathrm{r}}}{\partial \mathrm{z}^{2}}\right) \\
\rho\left(\frac{\partial \mathrm{v}_{\mathrm{z}}}{\partial \mathrm{t}}+\mathrm{v}_{\mathrm{r}} \frac{\partial \mathrm{v}_{\mathrm{z}}}{\partial \mathrm{r}}+\mathrm{v}_{\mathrm{z}} \frac{\partial \mathrm{v}_{\mathrm{z}}}{\partial \mathrm{z}}\right)=-\frac{\partial \mathrm{p}}{\partial \mathrm{z}}+ \\
\mu\left(\frac{\partial^{2} \mathrm{v}_{\mathrm{z}}}{\partial \mathrm{r}^{2}}+\frac{1}{\mathrm{r}} \frac{\partial \mathrm{v}_{\mathrm{z}}}{\partial \mathrm{r}}+\frac{\partial^{2} \mathrm{v}_{\mathrm{z}}}{\partial \mathrm{z}^{2}}\right)
\end{gathered}
$$

where, $\mathrm{r}$ and $\mathrm{z}$ are the cylindrical coordinates, $\mathrm{m} ; \mathrm{p}$ the pressure, $\mathrm{Pa} ; \rho$ the fluid density, $\mathrm{kg} / \mathrm{m}^{3} ; \mathrm{v}_{\mathrm{r}}$ and $\mathrm{v}_{\mathrm{z}}$ the fluid velocities, $\mathrm{m} / \mathrm{s}$; t the time, $\mathrm{s}$; and $\mu$ the viscosity, N. $\mathrm{s} / \mathrm{m}^{2}$.

The dependence of the velocity field on the spatial variation of the equivalent fluid average properties will be investigated and, if necessary, added to the model in a follow up study.

For the catalytic cracking reaction simulation, a 6 lump model (Fig. 2) provided by Petrobras Six, 2001, was adopted.

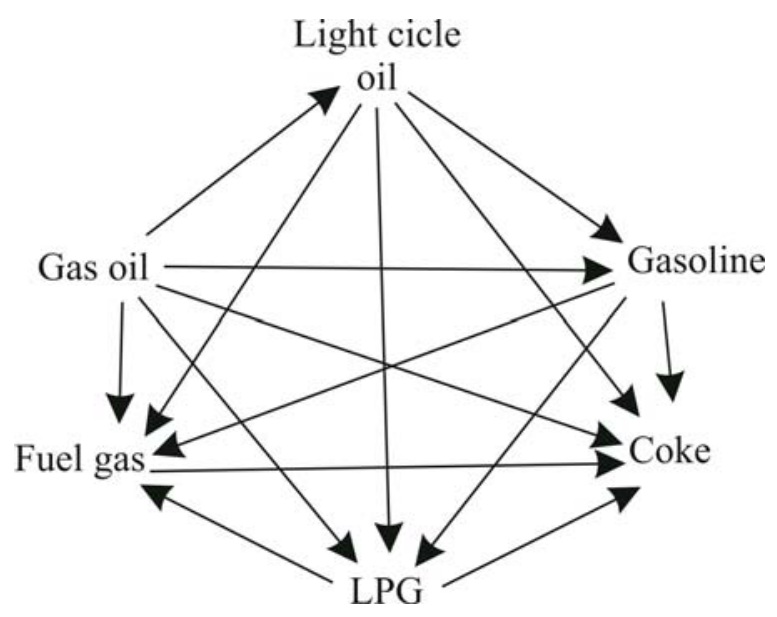

Fig. 2 - Lumped kinetic scheme

Equation (4) combined with Eqs. (5)-(9) represents the kinetic model set of equations. Eventhough this kinetic model is constructed with only 6 lumps, it is still possible to predict the key FCC products separately. Another import thing to be noticed is that the adsorption is also included in the kinetic model. 


$$
\begin{aligned}
& \frac{\partial \mathrm{C}_{\mathrm{i}}}{\partial \mathrm{t}}+\mathrm{v}_{\mathrm{r}} \frac{\partial \mathrm{C}_{\mathrm{i}}}{\partial \mathrm{r}}+\mathrm{v}_{\mathrm{z}} \frac{\partial \mathrm{C}_{\mathrm{i}}}{\partial \mathrm{z}}=\Omega_{\mathrm{i}} \\
& \Omega_{\mathrm{i}}=\left[\sum_{\mathrm{j}=1}^{\mathrm{i}-1} \mathrm{M}_{\mathrm{j}} \mathrm{K}_{\mathrm{j}, \mathrm{i}}^{\prime}\left(\mathrm{C}_{\mathrm{j}}^{*}\right)^{\mathrm{n}_{\mathrm{j}, \mathrm{i}}}-\sum_{\mathrm{j}=\mathrm{i}+1}^{\mathrm{N}} \mathrm{M}_{\mathrm{i}} \mathrm{K}_{\mathrm{i}, \mathrm{j}}^{\prime}\left(\mathrm{C}_{\mathrm{i}}^{*}\right)^{\mathrm{n}_{\mathrm{i}, \mathrm{j}}}\right] \times \frac{\rho_{\mathrm{cat}}}{\mathrm{M}_{\mathrm{i}}} \\
& \mathrm{C}_{\mathrm{i}}^{*}=\frac{1-\varepsilon}{\varepsilon} \rho_{\text {cat }} \mathrm{K}_{\mathrm{ad}, \mathrm{i}}^{\prime} \mathrm{C}_{\mathrm{i}} \\
& \mathrm{K}_{\mathrm{i}, \mathrm{j}}^{\prime}=\mathrm{K}_{\mathrm{i}, \mathrm{j}} \mathrm{e}^{\left(\frac{-\mathrm{E}_{\mathrm{i}, \mathrm{j}}}{\mathrm{RT}_{\mathrm{cat}}}\right)} \\
& \mathrm{K}_{\mathrm{ad}, \mathrm{i}}^{\prime}=\mathrm{K}_{\mathrm{ad}, \mathrm{i}} \mathrm{e}^{\left(\frac{-\mathrm{E}_{\mathrm{ad}, \mathrm{i}}}{\mathrm{RT}}\right)} \\
& \phi=\mathrm{e}^{\left(-406.4 \mathrm{C}_{\mathrm{c}}\right)} \\
& \mathrm{C}_{\mathrm{c}}=\frac{\mathrm{M}_{\text {coke }} \mathrm{C}_{\text {coke }}}{\mathrm{C}_{\text {cat }}^{\text {in }}}
\end{aligned}
$$

where, $\mathrm{C}_{\mathrm{i}}-$ lump concentration, $\mathrm{kmol} / \mathrm{m}^{3} ; \Omega_{\mathrm{i}}-$ reaction term of lump i, $\mathrm{kmol} / \mathrm{m}^{3} \mathrm{~s} ; \mathrm{C}_{\mathrm{c}}-$ coke concentration, $\mathrm{kg}_{\text {coke }} / \mathrm{kg}_{\text {cat }} ; \mathrm{E}$ - activation energy, $\mathrm{kJ} / \mathrm{kmol} \mathrm{K} ; \mathrm{K}$ - reaction pre-exponential constant, $\mathrm{m}^{3} / \mathrm{kg}_{\text {cat }} \mathrm{s}$ or $\mathrm{m}^{6} / \mathrm{kmol} \mathrm{kg}_{\text {cat }} \mathrm{s} ; \mathrm{M}-$ molecular weight, $\mathrm{kg} / \mathrm{kmol} ; \mathrm{n}$ - reaction order; $\mathrm{N}$ - number of lumps; $\mathrm{R}$ - universal gas constant $\mathrm{kJ} / \mathrm{kmol} \mathrm{K}$; $\mathrm{T}$ temperature, $\mathrm{K} ; \varepsilon$ - porosity and $\phi$ - catalyst deactivation function. The subscripts "ad" and "cat" represent adsorption and catalyst, respectively. The superscript "in" means input.

Finally, to complete the formulation, two more equations are necessary, the catalyst and the gas energy equations. Eventhough a one-phase model was presented in the fluid flow formulation, two energy equations are necessary to characterize a temperature gradient between gas and particulate. In the reaction term (Eq. (5)), the catalyst temperature is used to calculate the reaction kinetics constants, while for the heat exchange between the particulate and gaseous phases a second energy equation (gas equation) is necessary. The two energy equations are written as follows

$$
\begin{array}{r}
\mathrm{M}_{\text {cat }} \mathrm{C}_{\text {cat }} \mathrm{Cp}_{\text {cat }}\left(\frac{\partial \mathrm{T}_{\text {cat }}}{\partial \mathrm{t}}+\mathrm{v}_{\mathrm{r}} \frac{\partial \mathrm{T}_{\text {cat }}}{\partial \mathrm{r}}+\mathrm{v}_{\mathrm{z}} \frac{\partial \mathrm{T}_{\text {cat }}}{\partial \mathrm{z}}\right)= \\
\sum_{\mathrm{i}=1}^{\mathrm{N}}\left[\sum_{\mathrm{j}=\mathrm{i}+1}^{\mathrm{N}}\left[\left(-\Delta \mathrm{H}_{\mathrm{ij}}\right) \Omega_{\mathrm{j}} \mathrm{M}_{\mathrm{j}}\right]\right]+\mathrm{hA}_{\mathrm{gs}}\left(\mathrm{T}_{\text {cat }}-\mathrm{T}_{\text {gas }}\right) \\
\left(\sum_{\mathrm{j}=1}^{\mathrm{N}} \mathrm{M}_{\mathrm{j}} \mathrm{C}_{\mathrm{j}} \mathrm{Cp}_{\mathrm{j}}+\rho_{\mathrm{st}} \mathrm{Cp}_{\mathrm{st}}\right) \\
\left(\frac{\partial \mathrm{T}_{\text {gas }}}{\partial \mathrm{t}}+\mathrm{v}_{\mathrm{r}} \frac{\partial \mathrm{T}_{\text {gas }}}{\partial \mathrm{r}}+\mathrm{v}_{\mathrm{z}} \frac{\partial \mathrm{T}_{\text {gas }}}{\partial \mathrm{z}}\right)= \\
-\mathrm{hA}_{\mathrm{gs}}\left(\mathrm{T}_{\text {cat }}-\mathrm{T}_{\text {gas }}\right)
\end{array}
$$

where, the not yet defined variables are: $\mathrm{Cp}$ - specific heat, $\mathrm{kJ} / \mathrm{kg} \mathrm{K} ; \Delta \mathrm{H}$ - reaction enthalpy, $\mathrm{kJ} / \mathrm{kg} ; \mathrm{h}$ - gas-particulate heat transfer coefficient, $\mathrm{kJ} / \mathrm{m}^{2} \mathrm{~s} \mathrm{~K} ; \mathrm{A}_{\mathrm{gs}}$ - specific surface area of the particulate based on the unit reactor volume, $\mathrm{m}^{2} / \mathrm{m}^{3}$. The subscripts "cat", "gas" and "st" indicate catalyst-phase, gas-phase and steam, respectively.

\section{PRELIMINARY RESULTS}

A preliminary step before solving the set of differential equations (Eqs. (1)-(4), (11) and (12)) was to solve a simplified one-dimensional, steady state problem. This was made to evaluate the kinetic model behavior and to test the model sensibility to operating conditions changes. A fourth order Runge-Kutta method was used to solve the simplified set of differential equations given by

$$
\begin{aligned}
& \varepsilon \mathrm{V}_{\text {in }} \frac{\partial \mathrm{C}_{\mathrm{i}}}{\partial \mathrm{z}}=\Omega_{\mathrm{i}} \\
& \frac{\dot{\mathrm{m}}_{\text {cat }} \mathrm{Cp}_{\text {cat }}}{\mathrm{A}} \frac{\partial \mathrm{T}_{\text {cat }}}{\partial \mathrm{z}}= \\
& \sum_{\mathrm{i}=1\left[\sum_{\mathrm{j}=\mathrm{i}+1}^{\mathrm{N}}\left[\left(-\Delta \mathrm{H}_{\mathrm{ij}}\right) \Omega_{\mathrm{j}} \mathrm{M}_{\mathrm{j}}\right]\right]+\mathrm{hA}_{\text {gs }}\left(\mathrm{T}_{\text {cat }}-\mathrm{T}_{\text {gas }}\right)}^{\left(\dot{\mathrm{m}}_{\text {gasoil }} \mathrm{Cp}_{\text {gasoil }}+\dot{\mathrm{m}}_{\mathrm{st}} \mathrm{Cp}_{\mathrm{st}}\right)} \frac{\partial \mathrm{T}_{\text {gas }}}{\partial \mathrm{z}}= \\
& \mathrm{A}-\mathrm{hA}_{\text {gs }}\left(\mathrm{T}_{\text {cat }}-\mathrm{T}_{\text {gas }}\right)
\end{aligned}
$$

where the new variables are: $V_{\text {in }}$ - mixture average input velocity, $\mathrm{m} / \mathrm{s} ; \dot{\mathrm{m}}$ - mass flux, $\mathrm{kg} / \mathrm{s}$, and $\mathrm{A}$ - riser cross section area, $\mathrm{m}^{2}$.

The problem sketch for the one-dimensional model is similar to that shown in Fig. 1, with the only difference that the gas oil is injected at the bottom of the riser. The FCC riser characteristics and operating conditions are presented in Table 1.

The temperature and concentrations solutions for the one-dimensional model are shown in Fig. 3. This simple model was already able to predict the dependence between the catalyst temperature and the gas oil conversion. It is possible to see in Fig. 3 that, as expected, the gas oil consumption and products formation are greater when the catalyst temperature is high and that it is at the bottom (first few meters) of the riser where the majority of the reactions occur. Another important phenomena observed in Fig. 3 is that at high temperatures the rate of formation of light cycle oil is higher than the rate of gasoline formation.

\begin{tabular}{lc}
\hline \multicolumn{2}{c}{ Table 1. Riser characteristics and operating conditions } \\
\hline Geometry & 18 \\
Length $(\mathrm{m})$ & 0.0508 \\
Diameter $(\mathrm{m})$ &
\end{tabular}

\section{Feedstock}

Gas oil mass flux $(\mathrm{kg} / \mathrm{h})$

Water vapor mass flux $(\mathrm{kg} / \mathrm{h})$

Catalyst oil ratio

\section{Physical parameters}

Catalyst density $\left(\mathrm{kg} / \mathrm{m}^{3}\right)$

Catalyst specific heat $(\mathrm{kJ} / \mathrm{kg} \mathrm{K}) \quad 1.09$

Catalyst input temperature $\left({ }^{\circ} \mathrm{C}\right) \quad 670$

Gas oil density $\left(\mathrm{kg} / \mathrm{m}^{3}\right) \quad 10$

Gas oil input temperature $\left({ }^{\circ} \mathrm{C}\right) \quad 200$

Water vapor density $\left(\mathrm{kg} / \mathrm{m}^{3}\right) \quad 0.5$

Water vapor specific heat $(\mathrm{kJ} / \mathrm{kg} \mathrm{K}) \quad 2.0$

Water vapor input temperature $\left({ }^{\circ} \mathrm{C}\right)$ 


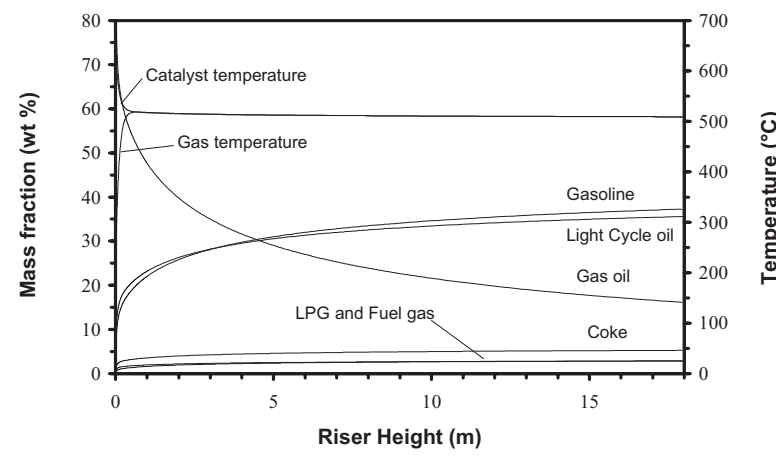

Fig. 3 - Runge-Kutta solution

With these results obtained with the onedimensional Runge-Kutta solution, the same problem (with the gas oil injected at the bottom of the riser) was solved with a bi-dimensional finite differences scheme. The solution grid used had $8 \times 70$ volumes.

Similar temperature and concentrations profiles were obtained, but now a bi-dimensional concentration and temperature fields are available. The temperature fields for the catalyst and the gas (gas oil + water vapor) are shown in Fig. 4.

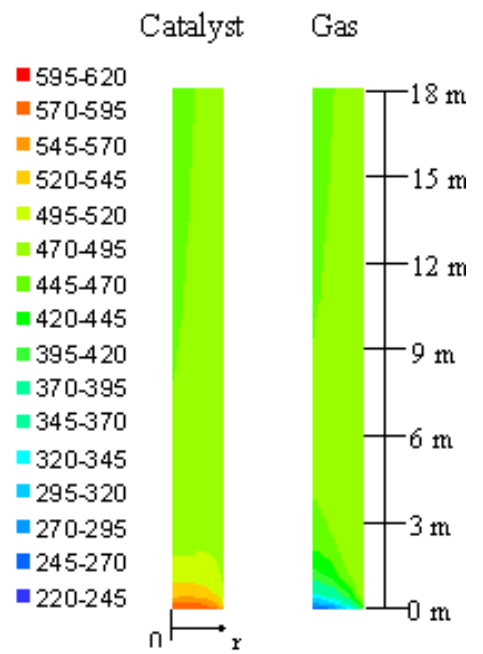

Fig. 4 - Bi-dimensional temperature fields $\left({ }^{\circ} \mathrm{C}\right)$

The concentration fields for the gas oil, light cycle oil and gasoline are presented in Fig. 5. The bi-dimensional mass fractions are calculated by

$$
\mathrm{Y}_{\mathrm{k}}^{\mathrm{i}}=\frac{\dot{\mathrm{m}}_{\mathrm{k}}^{\mathrm{i}}}{\dot{\mathrm{m}}_{\text {total }}}
$$

where, $\mathrm{Y}_{\mathrm{k}}^{\mathrm{i}}$ and $\dot{\mathrm{m}}_{\mathrm{k}}^{\mathrm{i}}$ are the mass fraction and mass flux of component $\mathrm{i}$ at volume $\mathrm{k}$, respectively and $\dot{\mathrm{m}}_{\text {total }}$ is the input gas oil mass flux.

The mass fractions of the LPG, fuel gas and coke lumps are presented in Fig. 6.

\section{J. A. Souza et al. Numerical Simulation..}

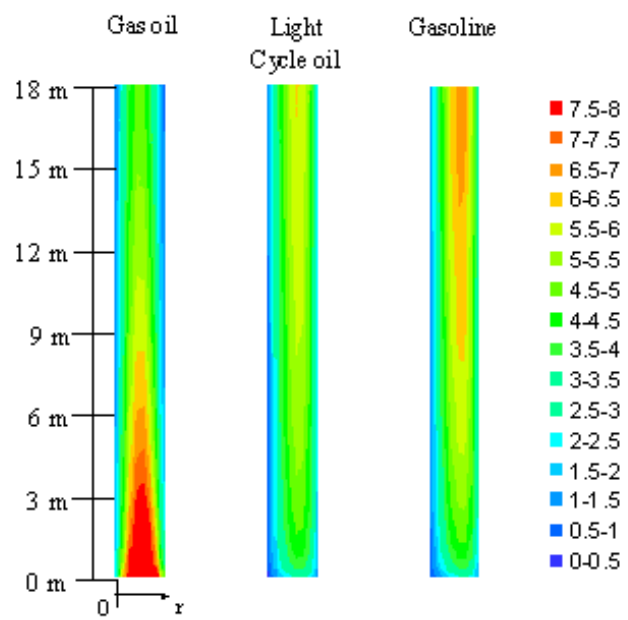

Fig. 5 - Gas oil, light cycle oil and gasoline mass fraction fields (wt \%)

The bi-dimensional solution with the radial gas oil injection is under development. Eventhough, it looks pretty simple to change the gas oil injection from the riser bottom to a radial position, the high gradients of temperature, concentration and velocity at the inlet zone make the numerical solution much more complex. Depending on the riser configuration and input mass fluxes, the numerical solution convergence is achieved or not. Since no general solution is available for this case yet, the authors decided not include any preliminary solution.

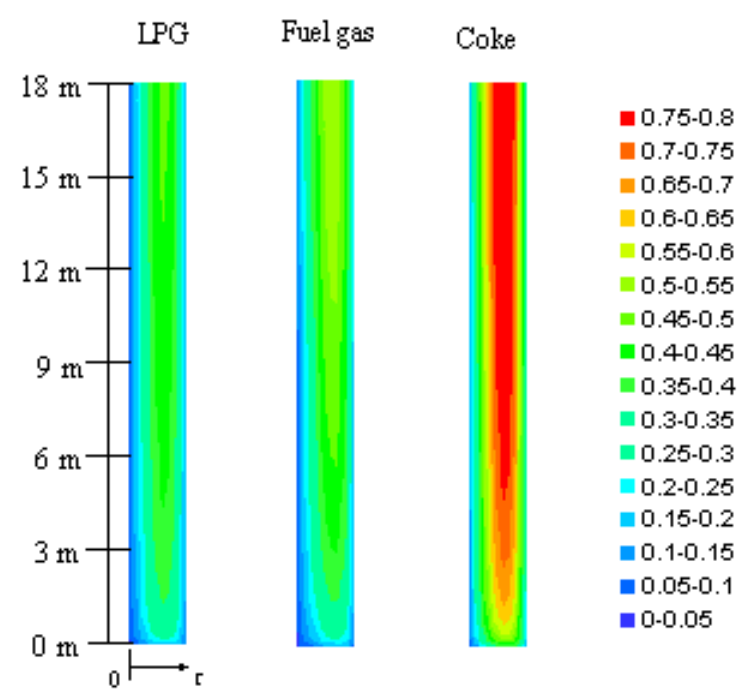

Fig. 6 - LPG, fuel gas and coke mass fraction fields (wt \%)

\section{CONCLUSIONS}

There is a lack of agreement among scientists about the most appropriate formulation model for FCC risers. The most complex models are normally suitable for units design, while the simple ones are used for units' control. The present model was constructed with the main goal of creating a fast and enough accurate computational code, not as simple as the plug flow models, but also not as complex as the three-dimensional and two-phase models. As it was shown in this paper, the proposed model has a 
simple incompressible formulation of the fluid flow and a six lump kinetic model to the catalytic cracking reactions.

The study presented in this work brings the preliminary results obtained with the proposed FCC riser reactor model. First, a one-dimensional fourth order Runge-Kutta solution was used to test the model. Next, the same solution was obtained with a bi-dimensional finite differences scheme and then, on a third step, a bidimensional model with radial injection of gas oil was discussed. The fourth and last step will be the formulation and implementation of a thermodynamic optimization methodology. This optimization will be based on the second law of thermodynamics and the concept of entropy generation minimization (Bejan, 1996).

\section{ACKNOWLEDGEMENTS}

The authors acknowledge with gratitude the support of the Program of Human Resources for the Oil Sector and Natural Gas, of the Brazilian Oil National Agency - PRH-ANP/MME/MCT, of project No 1121/00 CTPETRO/FINEP (Brazilian Projects and Studies Financing Agency) and of Petrobras Six (Brazilian Oil Co.).

\section{REFERENCES}

Ali, H and Rohani, S., 1997, "Dynamic Modeling and Simulation of a Riser-Type Fluid Catalytic Cracking Unit", Chem. Eng. Technol., Vol. 20, p. 118-130.

Bejan, A., 1996, Entropy Generation Minimization, Wiley, New York.

Blasetti, A. and Lasa, H. de, 1997, "FCC Riser Unit Operated in the Heat-Transfer Mode: Kinetic Modeling", Ind. Eng. Chem. Vol. 36, p. 3223-3229.

Cerqueira, H. S., Biscaia, E. C. Jr. and Souza-Aguiar, E. F., 1997, "Mathematical Modeling and Simulation of Catalytic Cracking of Gasoil in a Fixed Bed: Coke Formation", Applied Catalysis A: General, Vol. 164, p. 35-45.

Cerqueira, H. S., Biscaia, E. C. Jr. and Souza-Aguiar, E. F., 1997a, "Mathematical Modeling of Deactivation by Coke Formation in the Cracking of Gasoil", Catalyst Deactivation, Vol. 111, p. 303-310, 1997.

Derouin, C. N. D., Forissier, M. W. G. and Bernard, J. R., 1997, "Hydrodynamics of Riser Unit and Their Impact on FCC Operation", Ind. Eng. Chem., Vol. 36, p. 4505-4515.

Gao, J., Xu, C., Lin, S. and Yang, G., 1999, "Advanced Model for Turbulent Gas-Solid Flow and Reaction in FCC Riser Reactors", AIChE Journal, Vol. 45, n. 5, p. 1095-1113.

Gao, J., Xu, C., Lin, S. and Yang, G., 2001, "Simulation of Gas-Liquid-Solid 3-Phase Flow and Reaction in FCC Riser Reactors", AIChE Journal, Vol. 47, n. 3, p. 677-692.

Han, I., S. and Chung, C-.B., 2001, "Dynamic Modeling and Simulation of a Fluidized Catalytic Cracking Process. Part I: Process Modeling”, Chemical Engineering Science, Vol. 56, p. 1951-1971.

Jacob, S. M., Gross, B., Voltz, S. E. and Weekman, V. W. Jr., 1976, "A lumping and Reaction Scheme for Catalytic Cracking", AIChE Journal, Vol. 22, n. 4. p. 701-713.

Juárez, J. A-., Isunza, F. L-. and Rodríguez, E. A-., 1999, "5-Lump Kinetic Model for Gas Oil Catalytic Cracking", Applied Catalysis A: General, Vol. 177, p. 227-235.

Martignoni, W. P., 1998, "Modelling and Simulation of FCC Riser Reactors: an Heterogeneous Approach”, Ph. D.
Dissertation, University of Western Ontario, Ontario, Canada.

Martignoni, W. and Lasa, H. I., 2001, "Heterogeneous Reaction Model for FCC Riser Units", Chemical Engineering Science, Vol. 56, p. 605-612.

Mathiesen, V., Solberg, T., Arastoopour, H. and Hjertager, B. H., 1999, "Experimental and Computational Study of Multiphase Gas/Particle Flow in a CFB Riser", AIChE Journal, Vol. 45, n. 12, p. 2503-2518.

Neri, A. and Gidaspow, D., 2000, "Riser Hydrodynamics: Simulation Using Kinetic Theory", AIChE Journal, Vol. 46, n. 1, p. 52-67.

Patience, G. S., Chaouki, J. Berruti, F. and Wong, R., 1992, "Scaling Considerations for Circulating Fluidized Bed Risers", Powder Technology, Vol. 72, p. 31-37.

Petrobras Six, 2001, "Projeto de Aperfeiçoamento de Riser de FCC”, Internal Report, São Mateus do Sul, PR, Brasil.

Pitault, I., Nevicato, M. F. and Bernard, J-. R., 1994, "Kinetic Model Based on a Molecular Description for Catalytic Cracking of Vacuum Gas Oil", Chemical Engineering Science, Vol. 49, n. 24A, p. 4249-4262.

Tsuji, Y., Tanaka, T. and Yonemura, S., 1997, "Cluster Patterns in Circulating Fluidized Beds Predicted by Numerical Simulation (Discrete Particle Model Versus TwoFluid Model)", Powder Technology, Vol. 95, p. 254-264.

Weekman, V. W. Jr. and Nace, D. N., 1970, "Kinetic of Catalytic Cracking Selectivity in Fixed, Moving, and Fluid Bed Reactors", AIChE Journal, Vol. 16, n. 3, p. 397-204. 